\title{
The intention to prevent sexual risk behaviors among the youth in Yangon, Myanmar
}

\author{
Ann Jirapongsuwan \\ Faculty of Public Health, Mahidol University, Bangkok, Thailand \\ Sithu Swe \\ World Health Organization Country Office for Myanmar, Yangon, Myanmar, and \\ Arpaporn Powwattana \\ Faculty of Public Health, Mahidol University, Bangkok, Thailand
}

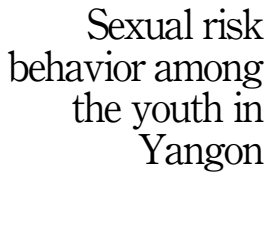

997

Received 10 December 2020 Revised 14 January 2021 Accepted 12 February 2021

\begin{abstract}
Purpose - The purpose of this paper is to investigate the intention to prevent sexual risk behaviors and associated factors among the youth in Yangon, Myanmar.

Design/methodology/approach - A cross-sectional descriptive research was undertaken among 192 youths. Participants included the youth residing in the study area and participated in the youth development program. Bivariate and multivariate logistic regressions were applied to identify an association.

Findings - The findings indicated that the proportion of a high level of intention to prevent sexual risk behaviors was $53.6 \%$. The factors associated with the intention to prevent sexual risk behaviors were: belief strength on sexual risk behaviors ( $\mathrm{aOR}=2.84 ; 95 \% \mathrm{CI}: 1.06-7.26)$, normative belief on the prevention of sexual risk behaviors ( $\mathrm{aOR}=2.03$; 95\% CI: 3.03-6.23), motivation to comply with preventing sexual risk behaviors $(\mathrm{aOR}=4.72 ; 95 \% \mathrm{CI}: 3.11-6.23)$, decision-making $(\mathrm{aOR}=2.46 ; 95 \% \mathrm{CI}: 2.22-5.41)$ and negotiation $(\mathrm{aOR}=6.3$; 95\% CI: 2.37-10.23)

Research limitations/implications - The study was a cross-sectional study and cannot establish causal relationships. These results can be a guideline for implementation for the youth but may limit the generalization of results to other age groups in Myanmar.

Practical implications - Findings can be used as a local and national public health guideline for developing interventions to prevent sexual risk behaviors.

Originality/value - Sexual risk behavior is considered taboo and puts Myanmar youths at risk of health and social problems. It is important for prevention efforts to determine factors related to sexual intentions to prevent the consequence of these problems.
\end{abstract}

Keywords Sexual risk behaviors, Theory of reasoned action, Youth, Prevention

Paper type Research paper

\section{Introduction}

Youths, defined as persons between the ages of 15 and 24 years, is the period of transition from the dependence of childhood to independent adulthood [1]. Young people, including youths, are a major human resource for development and key agents for social change, economic growth and technological innovation [2]. Thus, youth can be a positive force for development when provided with the opportunities they need to thrive. However, the second decade of life is often a turbulent period in which youths experience hormone changes, rapid physical, cognitive and emotional developments resulting in new behaviors as part of the pubertal changing process. Their behaviors and the way of responding to the problems and

(C) Ann Jirapongsuwan, Sithu Swe and Arpaporn Powwattana. Published in Journal of Health Research. Published by Emerald Publishing Limited. This article is published under the Creative Commons Attribution (CC BY 4.0) licence. Anyone may reproduce, distribute, translate and create derivative works of this article (for both commercial and non-commercial purposes), subject to full attribution to the original publication and authors. The full terms of this licence may be seen at http://creativecommons. org/licences/by/4.0/legalcode

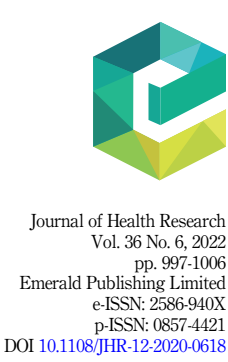


JHR

36,6

998 stimuli are particularly risky. One of the problems among youths across the world is engagement in sexual risk behaviors [3].

Sexual risk behavior is behavior that puts individuals at risk of unplanned pregnancy or a sexually transmitted infection [4]. They include premarital sex, early sexual initiation, unprotected sexual intercourse, sex with multiple partners and unprotected sex with partners who are potential carriers of sexually transmitted infections [5]. Many young people engage in sexual risk behaviors and experiences that can result in unintended health outcomes [3] The United Nations reported that approximately half of new human immunodeficiency virus (HIV) infections are among youths [1]. Findings from the Center for Disease Control and Prevention $(\mathrm{CDC})$ revealed that half of all new STDs reported each year are among youths. A study by the CDC also revealed a birth rate of $18.8 \% 1,000$ teen women. Moreover, pregnancy and birth are significant contributors to high school dropout rates among teen girls [2]. The prevalence of risky sexual health behaviors remains high and puts youths at higher risk of negative health outcomes and poor academic performance [3]. Therefore, monitoring the sexual risk behaviors of this vulnerable age group is necessary in order to control the consequence of those risky behaviors.

Youths in Myanmar are at risk of negative health impacts from sexual behaviors. Every year, almost 50,000 young girls in Myanmar give birth, and over 170 young girls die in pregnancy and childbirth. An estimated 36,000 young people are living with HIV [6]. The Department of Public Health in Myanmar reported that over 25\% of young people had their first birth before the age of 20 years, with a great proportion of teenagers bearing children in both rural and urban areas [7]. 5.9\% of young women reported teenage pregnancy and motherhood. The prevalence of HIV among females aged $15-24$ was at 0.3 and $0.4 \%$ among males [8]. Early pregnancies among young women have major health consequences for young mothers and their babies, such as eclampsia, puerperal endometritis and systemic infections [9]. Babies born to mothers under 20 years of age face higher risks of low birth weight, preterm delivery and severe neonatal conditions [10]. Pregnancy and childbirth complications are a leading cause of death among young women globally in low- and middleincome countries [10]. Regarding determinant factors related to such health problems, research shows that young people in Myanmar are engaging in risky sexual behaviors. They seem to have a limited understanding of sexual and reproductive health, with $38.0 \%$ of adolescents admitting they did not know a woman could become pregnant if she has sex only once, and only $16.67 \%$ of young people aged 15-24 have accurate HIV prevention knowledge [11]. The study of reproductive health issues among youths indicated that $60 \%$ of males had premarital sexual experience, whereas $7 \%$ of females had a sexual experience before marriage. More than $46 \%$ of sexually active high school students did not use a condom the last time they had sex [12]. The United Nations Population Fund (UNFPA) of Myanmar stated that sexual and reproductive health is considered taboo, making it challenging for young people to access accurate information that will help them make informed choices for their future [13].

Recently, in Myanmar, there have been discernible positive changes in every aspect of national development that are gaining momentum. As young people occupied nearly $28 \%$ of the total population, they are the main part of the national workforce, and the future of the nation relies on the personal development of every single young person [11]. The National Strategic Plan for Young People's Health (2016-2020) and the National Strategic Plan for Reproductive Health in Myanmar (2014-2018) were developed to ensure an effective and coordinated response to the reproductive health needs of youths in Myanmar [7]. Incorporation with professional agencies, including UN agencies, is an important objective of this plan that emphasizes the need for awareness-raising on health messages for young people to achieve positive behavior changes using appropriate and effective media and through peer education and counseling programs [7]. 
The United Nations Population Fund (UNFPA) and the Myanmar Medical Association (MMA) are working together to lay the foundation to strengthen health systems to improve the availability of high quality and equitable HIV/AIDS, sexual and reproductive health information and services among the population of the youth at risk. Programs can help young people adopt lifelong attitudes and behaviors that support their health and well-being including behaviors that can reduce their risk of HIV and other STDs.

The Youth Development Program (YDP) was established by the MMA in 2003 and was supported by the UNFPA in 2007. Program objectives were to disseminate basic health knowledge among youths and motivate them to adopt healthy behaviors [14]. It conducts a series of educational training, including basic life skills such as analytical skills, problemsolving skills, negotiation skills, assertiveness and decision-making skills in order to advise them on how to prevent risky sexual behaviors and to be protected from its consequences including unplanned pregnancies, sexually transmitted infections (STIs) and HIV-AIDS. More than 4,200 youths from different townships around Yangon are trained, and they became members of YDP. This program can be used as a training model to promote preventive sexual behavior among the youth in Myanmar. The program, however, has never been followed up, particularly regarding the expected preventive sexual risk behaviors. Therefore, it would be helpful to understand the situation of preventive sexual behaviors and related factors among youths who participated in that program.

The theoretical framework used as a basis for this study was the theory of reasoned action (TRA) [15]. This theory proposes that the decision to engage in sexual behavior can be predicted by an individual's intention to perform the behavior $[16,17]$. The behavioral intention is considered the predictor closest to behaviors and is influenced by the individual's attitude toward the behavior and subjective norm $[17,18]$. The attitude toward the behavior refers to the extent to which an individual has a favorable or unfavorable appraisal of a given behavior consisting of belief strength and belief evaluation of the outcome behavior [19]. Subjective norm is the social component of behavioral intentions consisting of normative belief and motivation to comply with. The TRA model has been applied in many studies related to behaviors of youths and has found that intentions did indeed predict sexual behavior [20-24]. A longitudinal study indicated that the sexual intentions of youths who had never had sex predicted their initiation of sexual intercourse [21]. However, there is little evidence revealed about sexual risk behavior among youths in Myanmar. Since the risk for negative health impacts from sexual behaviors has been increasing, it is important for prevention efforts to determine factors related to sexual intentions among them.

The results of this study will provide information related to the intention to prevent sexual risk behaviors among youths. Given the focus on the intention to prevent sexual risk behaviors, which is the most important determinant of behavior [15], it can be used to contribute to designing further prevention programs. It can also be used as evidence to prove the effectiveness of training of YDP to provide comprehensive youth-friendly health education and related program development.

\section{Methodology}

A cross-sectional descriptive study was conducted from January to February 2014 among youths in Yangon, Myanmar, to identify the intention to prevent sexual risk behaviors and associated factors. The population in the study was the youths who completed the YDP implemented by the Myanmar Medical Association between 2010 and 2013. A total of 192 youths was calculated from the formula for single proportion estimation [25]. To obtain the calculated subjects, the number of youths who completed the YDP in the year 2010, 2011, 2012 and 2013 was considered for proportional allocation. The inclusion criteria were single male and female, young people aged 15 to 24 years residing in the study area, who voluntarily 
JHR

36,6

participated in the study. Simple random sampling was used to choose the calculated subjects. Then they were informed about the purpose of the study and were asked to sign a consent form.

\section{Ethical issues}

All procedures were approved by the Ethics Committee (EC) for research on human subjects, Faculty of Public Health (FPH) and Mahidol University (Ref. No. MUPH 2014-019).

\section{Instruments}

Based on the literature and theory of reasoned action model, the self-administered questionnaires were developed by the researchers. Also, the mean was used as the cut-off point for the high and low levels of each part due to the normal distribution of data. Questionnaire items consisted of five parts as follows:

Part 1: The intention to prevent sexual risk behaviors included having premarital sex with a lover, having sex without a condom, having multiple sex partners and having sex with a commercial sex worker. Five items with a four-point Likert scale were used for rating. A higher rating indicated a greater intention to perform the four behaviors.

Part 2: General characteristics and basic life skills included decision-making and negotiation. The age, education level, guardian's occupation, having lovers and plan of marriage described the characteristics of the sample. A total of six items of decisionmaking skill and five items of negotiation skill were included in the scale. A four-point Likert scale from one (strongly disagree) to four (strongly agree) was used to measure basic life skills.

Part 3: Attitude toward the prevention of sexual risk behaviors including seven items of belief strength and eight items of belief evaluation regarding the outcomes of having sexual risk behaviors. A four-point Likert scale was adopted for the rating system. Higher ratings indicated more positive attitudes toward the prevention of sexual risk behaviors.

Part 4: Subjective norm of preventing sexual risk behaviors included five items of normative belief and five items of motivation to comply with preventing sexual risk behaviors that his/her friends or reference peer thought to do. A four-point Likert scale was adopted for the rating system. Higher ratings indicated a more positive subjective norm of preventing sexual risk behaviors.

Content validity was reviewed and approved by three experts in the fields of behavioral and medical sciences. The internal consistency reliability coefficients were also tested by pilot testing with 40 subjects who were not included in the final survey using Cronbach's alpha coefficient method. The result was that the content validity index (CVI) was in the range of $0.95-1.0$, and reliability was in the range of $0.71-0.87$.

The data collected were analyzed using SPSS for Windows version 18.0. Descriptive statistics were used for all variables. Bivariate and multivariate logistic regressions were applied to identify the association between general characteristics, basic life skills, attitude toward the prevention of sexual risk behaviors, the subjective norm of the prevention of sexual risk behaviors and intention to prevent sexual risk behaviors. Significance was set at a level of 0.05 .

\section{Results}

\section{Demographic characteristics}

A total of 192 respondents were included in the study, of which $53.1 \%$ were male. The age ranged from 15 to 24 years, with the average age of respondents being 20.8 years $(\mathrm{SD}=2.3)$. 
$44.8 \%$ of respondents had a bachelor's degree, and $44.3 \%$ attended a university or college. A total of $33.8 \%$ of participant's guardians were merchants. About $42 \%$ of respondents currently had a lover. Of this number, $2.5 \%$ had two and $1.2 \%$ had three lovers. $87.5 \%$ of respondents reported having a lover and indicated their intention to get married.

\section{Sexual risk behavior among the youth in Yangon}

\section{Intention to prevent sexual risk behaviors}

It was found that $53.6 \%$ of respondents were at a high level of intention to prevent sexual risk behaviors (Table 1). The highest percentage of respondents intended to avoid having sex with sex workers $(98.5 \%)$, followed by avoiding having multiple sex partners $(98.0 \%)$ and refrain from visiting a brothel/massage spa $(92.6 \%)$. However, $14.1 \%$ of respondents did not intend to avoid having premarital sex with a lover, and $15.1 \%$ did not intend to use a condom (Table 2).

More than half of the respondents were at a high level of negotiation skill (51.6\%) and normative belief (52.1\%), while decision making (61.5\%), belief strength $(54.7 \%)$, and belief evaluation $(55.2 \%)$ were at a low level. About half of the respondents were at a high level of motivation to comply with preventing sexual risk behaviors (Table 3).

\section{Factors associated with the intention to prevent sexual risk behaviors}

In the multiple logistic regression analysis, the factors significantly associated with intention to prevent sexual risk behaviors were: belief strength on sexual risk behaviors (adjusted Odds Ratio $(\mathrm{aOR})=2.84 ; 95 \%$ confidence interval $(\mathrm{CI}): 1.06-7.26)$, normative belief on the prevention of sexual risk behaviors ( $\mathrm{aOR}=2.03$; 95\% CI: 3.03-6.23), motivation to comply with preventing sexual risk behaviors ( $\mathrm{aOR}=4.72 ; 95 \% \mathrm{CI}: 3.11-6.23)$, decision- making $(\mathrm{aOR}=2.46 ; 95 \% \mathrm{CI}: 2.22-5.41)$ and negotiation $(\mathrm{aOR}=6.35 ; 95 \% \mathrm{CI}: 2.37-10.23)$ (Table 4).

\begin{tabular}{|c|c|c|c|c|c|c|c|}
\hline \multirow[b]{2}{*}{ The level of an intention to prevent sexual risk behaviors } & \multicolumn{2}{|c|}{ Male } & \multicolumn{2}{|c|}{ Female } & \multicolumn{2}{|c|}{ Total } & \multirow{5}{*}{$\begin{array}{r}\text { Table 1. } \\
\text { Frequency and } \\
\text { percentage of the level } \\
\text { of the intention to } \\
\text { prevent sexual risk } \\
\text { behaviors }\end{array}$} \\
\hline & $n$ & $\%$ & $n$ & $\%$ & $n$ & $\%$ & \\
\hline High & 55 & 53.9 & 48 & 53.3 & 103 & 53.6 & \\
\hline Low & 47 & 46.1 & 42 & 46.7 & 89 & 46.4 & \\
\hline $\operatorname{Min}=15 \operatorname{Max}=24 ;$ Mean $=20.63 \mathrm{SD}=2.7$ & & & & & & & \\
\hline
\end{tabular}

Intention to prevent sexual risk behaviors

\begin{tabular}{|c|c|c|c|c|c|c|c|c|c|}
\hline \multirow[b]{3}{*}{ Statement } & & \multirow{2}{*}{\multicolumn{2}{|c|}{$\begin{array}{l}\text { Strongly } \\
\text { disagree } \\
n(\%)\end{array}$}} & \\
\hline & \multicolumn{2}{|c|}{$\begin{array}{c}\text { Strongly agree } \\
n(\%)\end{array}$} & \multicolumn{2}{|c|}{$\begin{array}{l}\text { Agree } \\
n(\%)\end{array}$} & \multicolumn{2}{|c|}{$\begin{array}{c}\text { Disagree } \\
n(\%)\end{array}$} & & & \\
\hline & Male & Female & Male & Female & Male & Female & Male & Female & \\
\hline $\begin{array}{l}\text { Avoid having sex } \\
\text { with sex workers }\end{array}$ & $63(32.8)$ & $66(34.4)$ & $36(18.8)$ & 24 (12.5) & $0(0.0)$ & $0(0.0)$ & $3(1.6)$ & $0(0.0)$ & \\
\hline $\begin{array}{l}\text { Avoid having } \\
\text { multiple sex partners }\end{array}$ & $65(33.9)$ & $48(25.0)$ & $33(17.2)$ & $42(21.9)$ & 3 (1.6) & $0(0.0)$ & $1(0.5)$ & $0(0.0)$ & \\
\hline $\begin{array}{l}\text { Refrain from visiting } \\
\text { a brothel/massage spa }\end{array}$ & $53(27.6)$ & $62(32.3$ & $43(22.4)$ & 27 (14.1) & $5(2.6)$ & $1(0.5)$ & $1(0.5)$ & $0(0.0)$ & \\
\hline $\begin{array}{l}\text { Avoid having } \\
\text { premarital sex }\end{array}$ & 35 (18.2) & $43(22.4)$ & $48(25.0)$ & $39(20.3)$ & $16(8.3)$ & $7(3.6)$ & $3(1.6)$ & $1(0.5)$ & $\begin{array}{r}\text { Table } 2 . \\
\text { Frequency and }\end{array}$ \\
\hline $\begin{array}{l}\text { Intended to use a } \\
\text { condom when having } \\
\text { sex }\end{array}$ & $24(12.5)$ & $50(26.0)$ & $54(28.1)$ & $39(20.3)$ & $23(12.0)$ & $1(0.5)$ & $1(0.5)$ & $0(0.0)$ & $\begin{array}{r}\text { percentage of intention } \\
\text { to prevent sexual risk } \\
\text { behaviors }\end{array}$ \\
\hline
\end{tabular}


JHR

36,6

1002

\section{Discussion}

The intention to perform certain behaviors can predict the decision to engage in such behavior $[16,17]$. This research found that more than half of respondents had a high level of intention to prevent sexual risk behaviors, similar to the findings of the studies from Colombia [26], the United States [27] and Tanzania [28]. In this study, a high proportion of respondents intended to prevent sexual risk behaviors. Surprisingly, it was evident that about $15 \%$ of the respondents indicated little intention to avoid having premarital sex and to use condoms every time they had sex. Two-thirds of the respondents reported currently having lovers, and about 15\% disagreed with the option of having sex before marriage. This finding reveals that Myanmar youths engage in risky sexual behaviors, resulting in adverse health outcomes. A similar result was found in a study among Myanmar university students which reported about $16 \%$ of students had sex experience with someone-mostly with their boyfriends or girlfriends, with the condom being the most common method. $11 \%$ of students had an experience of pregnancy, and some of them were unwanted and ended with a miscarriage [29] The 2020 Myanmar national data showed that there is high unintended pregnancy among young women, but there are low levels of seeking support at public facilities due to social stigma [30]. This information suggests that Myanmar youths are at risk of unplanned pregnancy or a sexually transmitted infection [4]. Therefore, the promotion of avoiding having premarital sex and using condoms needs to be taken into consideration to emphasize a preventive behavior program.

Findings supported the TRA that the behavioral intention is influenced by an individual's attitude toward the behavior and subjective norm as well as basic life skills, which consisted of decision making and negotiation [19, 20]. The individual's intention to perform a specific behavior is achieved as a result of the interaction between behavioral and normative beliefs $[19,31]$. In the study, youths with high belief strength on sexual risk behaviors were more likely to intend to prevent sexual risk behaviors. Belief strength on such behaviors reflected the youths' acceptance that performing sexual risk behaviors will have unfavorable results, such as unintended pregnancy, HIV/AIDS or STDs. Similar findings were found in a study conducted in Colombia [26].

Regarding the subjective norm, youths with firm normative beliefs on the prevention of sexual risk behaviors and motivation to comply with such behaviors were more likely to intend to prevent sexual risk behaviors. Normative belief reflects the perception of youths regarding the approval of peers about sexual risk behavior and the motivation to comply with those behaviors [17]. The result is similar to studies conducted in Colombia and Taiwan $[26,32]$. All of the respondents reported a good relationship with their close friends. Studies conducted in Taiwan and Mexico showed that peers had a significant influence on the intention of sexual behaviors [17, 32]. Results showed that youths with high decision-making and negotiation skills were more likely to intend to prevent sexual risk behaviors. Basic life skills, including decision-making and negotiation skills, are internal factors that can influence the degree of control that an individual has over a given behavior [21]. A similar result was found in a study conducted in Taiwan [32]. However, a high proportion of the decision-

Table 3.

Numbers and percentage of independent factors

\begin{tabular}{lrrrrr}
\hline Independent factors & High $n(\%)$ & Low $n(\%)$ & Mean & SD & Min-Max \\
\hline Belief strength & $87(45.3)$ & $105(54.7)$ & 23.1 & 2.3 & $17-28$ \\
Belief evaluation & $86(44.8)$ & $106(55.2)$ & 25.2 & 3.1 & $11-32$ \\
Normative belief & $100(52.1)$ & $92(47.9)$ & 16.0 & 2.2 & $11-20$ \\
Motivation to comply & $97(50.1)$ & $95(49.5)$ & 16.6 & 2.2 & $10-20$ \\
Decision-making skills & $74(38.5)$ & $118(61.5)$ & 19.4 & 2.2 & $14-24$ \\
Negotiation skills & $99(51.6)$ & $93(48.4)$ & 17.4 & 1.9 & $12-20$ \\
\hline
\end{tabular}




\begin{tabular}{|c|c|c|c|c|c|}
\hline Factors & $\begin{array}{c}\text { Crude odds } \\
\text { ratio }\end{array}$ & $\begin{array}{l}95 \% \text { confidence } \\
\text { interval }\end{array}$ & $\begin{array}{l}\text { Adjusted odds } \\
\text { ratio }\end{array}$ & $\begin{array}{l}95 \% \text { confidence } \\
\text { interval }\end{array}$ & $\begin{array}{l}\text { Sexual risk } \\
\text { behavior among }\end{array}$ \\
\hline \multicolumn{5}{|c|}{ General characteristics } & Yangon \\
\hline \multicolumn{6}{|l|}{ Gender } \\
\hline Female & $\begin{array}{l}1 \\
1.23\end{array}$ & $1.76-3.54$ & 1.02 & $0.43-7.32$ & 1003 \\
\hline \multicolumn{6}{|l|}{ Age (yrs) } \\
\hline $15-20$ & 1 & & 1 & & \\
\hline Over 21 & 2.03 & $1.42-3.28$ & 3.12 & $0.88-4.72$ & \\
\hline \multicolumn{6}{|l|}{ Education level } \\
\hline Undergraduate & 1 & & 1 & & \\
\hline Graduate & 0.61 & $0.40-0.91$ & 0.76 & $0.09-0.55$ & \\
\hline \multicolumn{6}{|c|}{ Guardian's occupation } \\
\hline General services & 1 & & 1 & & \\
\hline Professional jobs & 1.33 & $1.05-2.51$ & 0.69 & $0.32-1.50$ & \\
\hline \multicolumn{6}{|l|}{ Having a lover } \\
\hline Yes & 1 & & 1 & & \\
\hline No & 1.88 & $1.06-3.34$ & 0.22 & $0.09-0.55$ & \\
\hline \multicolumn{6}{|c|}{ Attitude toward the prevention of sexual risk behaviors } \\
\hline \multicolumn{6}{|c|}{ Belief strength on sexual risk behaviors } \\
\hline Low & 1 & & 1 & & \\
\hline High & 2.17 & $1.27-3.64$ & 2.84 & $1.06-7.26$ & \\
\hline \multicolumn{6}{|c|}{ Belief evaluation of having a sexual risk } \\
\hline \multicolumn{6}{|c|}{ Behaviors } \\
\hline Low & 1 & & 1 & & \\
\hline High & 3.26 & $0.55-3.64$ & 3.34 & $0.23-6.02$ & \\
\hline \multicolumn{6}{|c|}{ Subjective norm of the prevention of sexual risk behaviors } \\
\hline \multicolumn{6}{|c|}{$\begin{array}{l}\text { Normative belief on the prevention of sexual } \\
\text { Risk behaviors }\end{array}$} \\
\hline $\begin{array}{l}\text { Risk behaviors } \\
\text { Low }\end{array}$ & 1 & & 1 & & \\
\hline High & 1.88 & $2.25-4.52$ & 2.03 & $3.03-6.23$ & \\
\hline \multicolumn{6}{|c|}{$\begin{array}{l}\text { Motivation to comply with preventing sexual } \\
\text { risk behaviors }\end{array}$} \\
\hline Low & 1 & & 1 & & \\
\hline High & 4.53 & $3.27-5.85$ & 4.72 & $3.11-6.23$ & \\
\hline \multicolumn{6}{|l|}{ Basic life skills } \\
\hline Decision making & & & & & Table 4. \\
\hline Low & 1 & & 1 & & The association \\
\hline High & 2.34 & $1.52-4.26$ & 2.46 & $2.22-5.41$ & $\begin{array}{l}\text { between factors and } \\
\text { intention to prevent }\end{array}$ \\
\hline Negotiation & & & & & sexual risk behaviors \\
\hline Low & 1 & & 1 & & in the multiple \\
\hline High & 6.05 & $3.53-9.56$ & 6.35 & $2.37-10.23$ & regression analysis \\
\hline
\end{tabular}

making skills were found at a low level. Possible reasons may be due to the family culture of Myanmar, where the relationship between parents and children is exceptionally strong, and older people always play a significant role in making decisions for younger people. Therefore, the increase in decision-making skills of youths in Myanmar should be a consideration. 
JHR

36,6

\section{Strength and limitation}

A key strength of the present study is its updating of sexual risk behaviors among youths in Myanmar. The data provide a better understanding of internal and external factors related to such behaviors. However, the study was limited by the methodological limitation of the crosssectional study; the factors and intention to prevent sexual risk behaviors are simultaneously assessed, which cannot establish causal relationships. With regard to the sensitive issue of sexual behavior, it is possible that participants may give socially desirable answers resulting in data bias.

\section{Conclusions}

This finding supported the success of the YDP program, where the UNFPA worked closely with the WHO and UNICEF on a global program to accelerate action to end child marriage and adolescent pregnancy [29]. The evidence stated the intention of preventing sexual risk behaviors can be made by individuals and social factors of the TRA model. Therefore, the promotion of attitudes toward the prevention of sexual risk behaviors, decision- making and negotiation skills as well as subjective norms particularly around peers could be taken into consideration for the desired prevention of sexual risk behaviors.

\section{Recommendation}

This research has thrown up questions in need of further investigation. Although intentions are certainly a major determinant in whether someone engages in a particular sexual behavior, further research is needed to understand what factors affect the strength of the intended behavior relationship. Moreover, more in-depth facility research, as well as longitudinal study concerning associated factors, should be investigated among general youths across the country. Further experimental studies regarding the intention of preventing sexual risk behaviors and associated factors would be beneficial. Despite the fact of TRA that behaviors are influenced by intention, other literature suggests the behavior may be elicited unintentionally. There are factors other than those specified by TRA that affect a youth's decision to engage in sexual behaviors. Thus, other factors such as family, social and environmental stimuli should be considered.

Conflict of Interest: None

\section{References}

1. United Nations. Definition of youth. [cited 2020 Feb]. Available from: https://www.un.org/esa/ socdev/documents/youth/fact-sheets/youth-definition.pdf.

2. Center for Disease Control and Prevention. About teen pregnancy. [updated 2019 Mar 1; cited 2020 Feb 14]. Available from: https:/www.cdc.gov/teenpregnancy/about/index.htm.

3. Center for Disease Control and Prevention [CDC]. Sexually transmitted disease surveillance. Atlanta: U.S. Department of Health and Human Services; 2017.

4. Dworsky A. The sexual and reproductive health of youth in foster care. In: Trejos-Castillo E, Trevino-Schafer N, editors. Handbook of foster youth. New York: Routledge; 2018. p. 133-54.

5. Bengel J. Sexual risk behaviors. In: Smelser NJ, Baltes PB, editors. International encyclopedia of the social \& behavioral sciences. Oxford: Pergamon; 2001. p. 14012-8.

6. Myanmar, United nations population Fund [UNFPA]. Annual report 2018. [cited 2020 Feb]. Available from: https:/myanmar.unfpa.org/sites/default/files/pub-pdf/Annual Report UNFPA Myanmar 2018.pdf.

7. Myanmar, Ministry of Health, Department of Public Health. Five-year strategic plan for young people's health; 2016-2020. [cited 2020 February]. Available from: https:/mohs.gov.mm/Main/ content/publication/youth-five-year-strategic-plan-for-young-peoples-health-2016-2020. 
8. World Bank. Prevalence of HIV. [cited 2020 Feb]. Available from: https://data.worldbank.org/ indicator/SH.HIV.1524.MA.ZS?locations =PW-MM.

9. World Health Organization [WHO]. Global health estimates 2015: deaths by cause, age, sex, by country and by region, 2000-2015. Geneva: WHO; 2016.

10. World Health Organization [WHO]. Adolescent pregnancy. [updated 2020 Jan 31; cited 2020 Feb]. Available from: https://www.who.int/news-room/fact-sheets/detail/adolescent-pregnancy.

11. United Nations Educational, Scientific and Culture Organization [UNESCO]. Positive health, education and gender equality outcomes for Myanmar youth [updated 2019 Apr 17; cited 2020 Mar]. Available from: https://en.unesco.org/news/positive-health-education-and-gender-equalityoutcomes-myanmar-youth.

12. Kann L, McManus T, Harris WA, Shanklin SL, Flint KH, Queen B, et al. Youth risk behavior surveillance - United States, 2017. MMWR Surveill Summ. 2018; 67(8): 1-114. doi: 10.15585/mmwr. ss6708a1.

13. Myanmar, United Nations Population Fund [UNFPA]. Young people. [cited 2020 Jan]. Available from: https://myanmar.unfpa.org/en/node/15283.

14. Myanmar Medical Association [MMA]. Youth development project. [updated 2016; cited 2020 Jan] Available from: https://www.mmacentral.org/projects/youth-development-project/.

15. Ajzen I, Fishbein M. Understanding attitudes and predicting social behavior. New Jersey: Prentice-Hall; 1980.

16. Fishbein M, Ajzen I. Predicting and changing behavior: the reasoned action approach. New York: Psychology Press; 2010.

17. Márquez Vega MA, Benavides Torres RA, Gallegos Cabriales EC . Sexual communication of parents and children: the theory of reasoned action and planned behavior. Biomed J Sci Tech Res. 2019; 19(3): 14272-5. doi: 10.26717/bjstr.2019.19.003290.

18. Forehand R, Gound M, Kotchick BA, Armistead L, Long N, Miller KS. Sexual intentions of black preadolescents: associations with risk and adaptive behaviors. Perspect Sex Reprod Health. 2005; 37(1): 13-8. doi: 10.1363/psrh.37.13.05.

19. Ajzen I. Martin Fishbein's legacy: the reasoned action approach. Ann Am Acad Pol Soc Sci. 2012; 640(1): 11-27. doi: 10.1177/0002716211423363.

20. Doswell WM, Braxter BJ, Cha E, Kim KH. Testing the theory of reasoned action in explaining sexual behavior among African American young teen girls. J Pediatr Nurs. 2011; 26(6): e45-54. doi: 10.1016/j.pedn.2011.03.007.

21. Stanton BF, Li X, Black MM, Ricardo I, Galbraith J, Feigelman S, et al. Longitudinal stability and predictability of sexual perceptions, intentions, and behaviors among early adolescent AfricanAmericans. J Adolesc Health. 1996; 18(1): 10-9. doi: 10.1016/1054-139x(95)00070-9.

22. Dippel EA, Hanson JD, McMahon TR, Griese ER, Kenyon DB. Applying the theory of reasoned action to understanding teen pregnancy with American Indian communities. Matern Child Health J. 2017; 21(7): 1449-56. doi: 10.1007/s10995-017-2262-7.

23. de Ravello L, Everett Jones S, Tulloch S, Taylor M, Doshi S. Substance use and sexual risk behaviors among american Indian and Alaska native high school students. J Sch Health. 2014; 84(1): 25-32. doi: 10.1111/josh.12114.

24. Jemmott LS, Jemmott JB, Villarruel AM. Predicting intentions and condom use among Latino college students. J Assoc Nurses AIDS Care. 2002; 13(2): 59-69. doi: 10.1016/s1055-3290(06)60201-x.

25. Daniel WW. Biostatistics: basic concepts and methodology for health sciences. 9th ed. Hoboken, NJ: John Wiley \& Sons; 2010.

26. Morales A, Vallejo-Medina P, Abello-Luque D, Saavedra-Roa A, García-Roncallo P, Gomez-Lugo $\mathrm{M}$, et al. Sexual risk among Colombian adolescents: knowledge, attitudes, normative beliefs, perceived control, intention, and sexual behavior. BMC Publ. Health. 2018; 18(1): 1377. doi: 10. 1186/s12889-018-6311-y. 
JHR

36,6

1006

27. Asare M. Using the theory of planned behavior to determine the condom use behavior among college students. Am J Health Stud. 2015; 30(1): 43-50.

28. Kalolo A, Kibusi SM. The influence of perceived behaviour control, attitude and empowerment on reported condom use and intention to use condoms among adolescents in rural Tanzania. Reprod. Health. 2015; 12: 105. doi: 10.1186/s12978-015-0097-5.

29. Myitzu TO, Thida, Khaing NT, Kyaw TS, Yadanar A, Theingi M. Sexual experience and contraceptive use among unmarried adolescent university students in Mandalay, Myanmar. Public Health Open Access. 2019; 3(1): 000132. doi: 10.23880/phoa-16000132.

30. Myanmar, Ministry of Health and Sport. Myanmar family planning landscape analysis. [updated 2017 Apr; cited $2020 \mathrm{Feb}$. Available from: https://www.familyplanning2020.org/sites/default/files/ Jhpiego-FP2020-FP-Landscape-Analysis_final-approved.pdf.

31. Muhammad NA, Shamsuddin K, Mohd Amin R, Omar K, Thurasamy R. Questionnaire development and validity to measure sexual intention among youth in Malaysia. BMC Publ. Health. 2017; 17(1): 157. doi: 10.1186/s12889-016-3949-1.

32. Tseng YH, Cheng CP, Kuo SH, Hou WL, Chan TF, Chou FH. Safe sexual behaviors intention among female youth: the construction on extended theory of planned behavior. J Adv Nurs. 2020; 76(3): 814-23. doi: 10.1111/jan.14277.

\section{Corresponding author}

Ann Jirapongsuwan can be contacted at: ann.jir@mahidol.ac.th

For instructions on how to order reprints of this article, please visit our website:

www.emeraldgrouppublishing.com/licensing/reprints.htm

Or contact us for further details: permissions@emeraldinsight.com 